\title{
EDITORIAL
}

\section{On the road: the progress of Light: Science \& Applications}

\author{
Light: Science \& Applications (2013) 2, e49; doi:10.1038/Isa.2013.5; published online 4 January 2013
}

$\mathrm{W}$ ith time passing imperceptibly, as a new journal published in collaboration with the Nature Publishing Group (NPG), Light: Science \& Applications truly and mightily attracted the attention of international peers in optics and photonics through the course of nearly a year since launching the new-born journal. When the New Year is gently approaching, on behalf of the editorial board of Light: Science \& Applications, we would like to express our deep gratitude to the readers, authors and reviewers accompanying Light: Science \& Applications to grow up robustly. We sincerely and gratefully thank all of you for your strong and consistent support!

As we all know, the diversity and richness of manuscripts from global sources is the roadmap and landmark of an international journal with a potential for much higher impact. Only from original papers and reviews all over the world through internationalization, we can select high-quality papers to meet the leading academic standards. Ever since founded on 29 March 2012, relying on the international editorial board members and editors around the world as well as the international publicity of NPG, Light: Science \& Applications has accumulated optics experts from 78 research institutions and universities in 20 countries and regions to submit 78 invited and contributed papers on their most recent research. Through a rigorous review process, 27 peer-reviewed papers from 12 countries and regions were formally accepted for publications (Figure 1). In 2012, Light: Science \& Applications published 22 papers from 22 universities and research institutions all over the world (Supplementary Tab. 1).

Simultaneously, the international editorial board of Light: Science \& Applications, as the academic leadership and decision-making body, plays a crucial and key role in the construction and development of the new journal. The international editorial board members are not only working on the peer-review process, the manuscript editing or the paper contribution by themselves, but also advocating Light: Science \& Applications worldwide to gain its vigorous publicity with the patency of international academic exchange. Professor Jianlin Cao from Ministry of Science and Technology of China serves as the editor-in-chief, while Professor Tianhong Cui from the University of Minnesota in USA and Dr Stefan Kaierle from Laser Center Hannover in Germany as co-executive editors-in-chief. Moreover, Light: Science \& Applications has 28 internationally renowned experts from nine countries serving as board members and editors working on 10 different topics in optics (Figure 2 and Supplementary Tab. 2). The editors are responsible for the peer-review process of manuscripts and making recommendations on high-quality papers. On 16 September 2012, the editorial department of Light: Science \& Applications at Changchun Institute of Optics, Fine Mechanics and Physics (CIOMP) of the
Chinese Academy of Sciences organized the 2012 editorial board meeting in Changchun, China. The attendees making a deliberate trip to participate in the board meeting include Professor Hans Zappe from the University of Freiburg in Germany, Professor John Love from the Australian National University, Professor Qihuang Gong from Peking University, Professor Hongbo Sun from Jilin University, Professor Xiaocong Yuan from Nankai University, Professor Min Qiu from Zhejiang University, Professor Min Gu from Australia Academy of Sciences, Professors Zhaoxiang Zhu and Michael Fiddy from North Carolina University, Professor Xuejun Zhang from the CIOMP, Dr Nick Campbell as a Nature Executive Editor from NPG, Ms Jie Bai as a senior publishing manager from NPG and Professor Jianlin Cao from Ministry of Science and Technology of China. As the editor-in-chief, we would like to take this opportunity to thank all of our editorial board members, editors and staff members for their very diligent and highly efficient work! As a new open-access journal, the international editorial team may also take an open and dynamic mode. With the further development of Light: Science \& Applications, we will invite and welcome more world-class experts in optics and photonics to join the editorial board.

The quality control of manuscripts is the core and central link in the editing and publishing of scientific journals. The international peerreview process can ensure the quality of publications to meet the international standards at a high level. Therefore, since launching journal at the very beginning, Light: Science \& Applications has been adhering to the rigorous peer-review process. Currently, the reviewer database of Light: Science \& Applications already has more than 3000 international experts. As of 31 October 2012, 150 international experts from 119 academic organizations in the world actively are involved in the peer-review process of our manuscripts (Supplementary Tab. 3). Hereby we express our heartfelt thanks for their professional service and strong support!

The digitization and networking of journal publications is one of the supporting systems for the internationalization of journals. To assist the co-publication of Light: Science \& Applications, the NPG makes full use of its extensive digital publishing experience and internationally renowned publishing platform to attract international scholars for papers browsing. This further expands readership and international visibility of the journal, to expedite the dissemination of scientific and technological achievements. The CIOMP of the Chinese Academy of Sciences, the co-publisher with the NPG, is the biggest, the strongest and the most comprehensive research institution in optics, known as 'the cradle of the Chinese optics'. Over the years, sponsored by the CIOMP, four Chinese journals including Optics and Precision Engineering, Journal of Luminescence, Chinese Optics and Liquid Crystal Display are published and promoted to be the core 

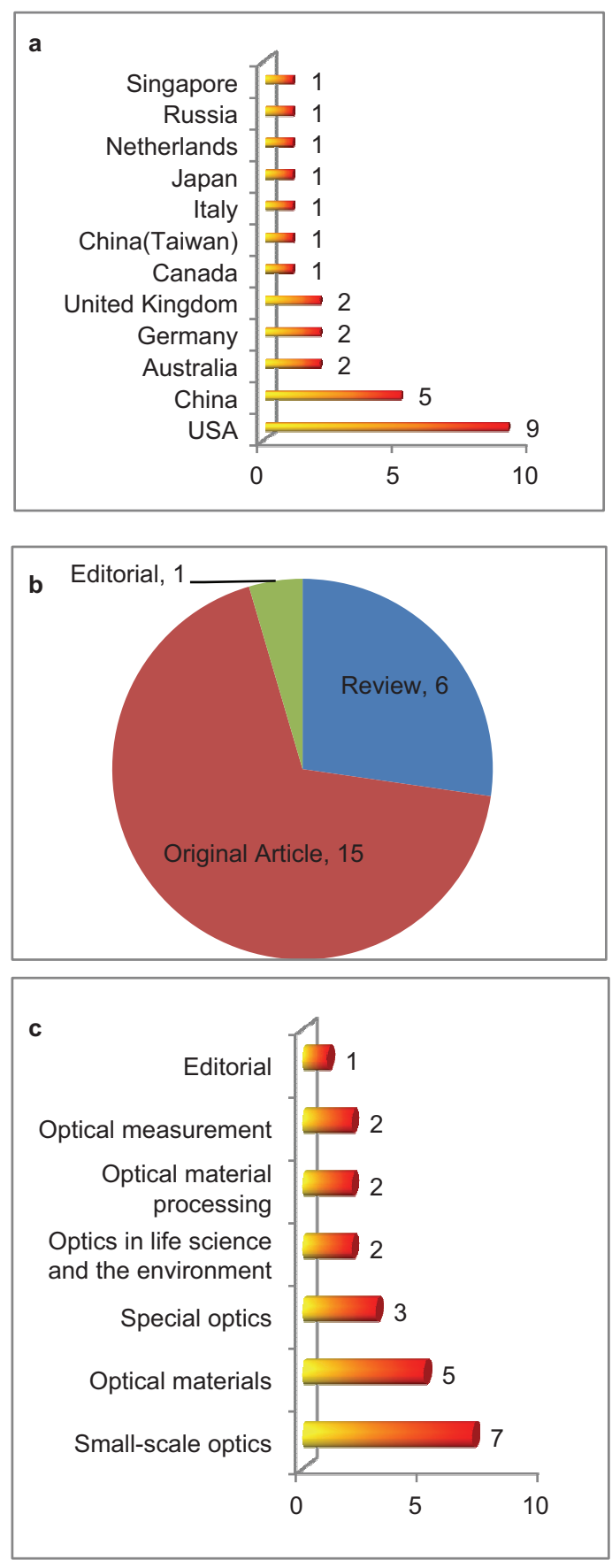

Figure 1 (a) Accepted papers by country/region. (b) Published papers by categories. (c) Published papers by research topics.

journals in their disciplines in China. For many years, the editorial department at the CIOMP accumulated very rich experience in the journal publishing business.

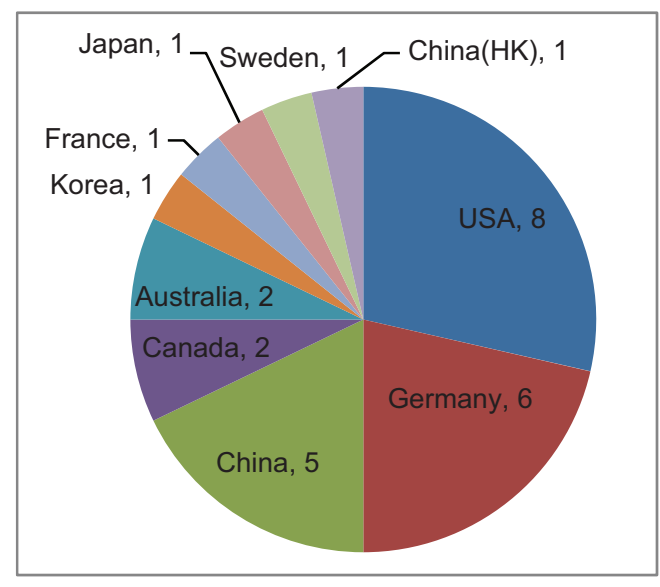

Figure 2 International board members by country/region.

Light: Science \& Applications will publish new theories, revolutionary technologies and innovative methods in the community of optics, based on a rigorous, fair and rapid peer-review process in a timely manner. We expect to provide an academic exchange platform at a high level for international scientific researchers and engineering personnel in optics and photonics.

The founding and establishment of a high-level international journal in optics has been a dream of several generations of researchers and editors at the CIOMP of Chinese Academy of Sciences. With many years of the publication foundation and experience from both the CIOMP and the NPG, we believe that Light: Science \& Applications will become one of the boutique journals in optics and photonics. We also believe that the advent of Light: Science \& Applications is bound to make a positive contribution to the spread of new knowledge in optics and the development of cause in optics globally.

Jianlin Cao

Editor-in-Chief

Vice Minister of Ministry of Science and Technology, Professor of Film Optics, State Key Laboratory of Applied Optics, CIOMP, Dong Nanhu Road 3888, Changchun, China

Tianhong Cui Executive Editor-in-Chief University of Minnesota Minneapolis, MN 55455, USA

This work is licensed under a Creative Commons Attribution-NonCommercial-NoDerivative Works 3.0 Unported License. To view a copy of this license, visit http:// creativecommons.org/licenses/by-nc-nd/3.0 